\title{
Yield displacement of slender cantilever RC walls as a function of the seismic demand features
}

\section{Desplazamiento de fluencia de muros esbeltos de hormigón armado como función de las características de la demanda sísmica}

\section{Victoria Rubina and Alejandro Morales}

Escuela de Ingeniería Civil, Universidad de Valparaíso, General Cruz 222, Valparaíso, Chile, vrubina.lazo@gmail.com, alejandro.morales@uv.cl

The yield displacement is a relevant parameter to design slender cantilever $R C$ walls under seismic actions. If the wall is expected to undergo inelastic excursions, then the yield displacement is used to estimate ductility demands, which are in turn used to design boundary elements (confinement reinforcing). In the last years, expressions to estimate the yield displacement have been proposed in several studies; many of them resorting to models with concentrated inelasticity. Results obtained with these models could be unrepresentative of the phenomenon studied, due to the assumption that the wall has elastic behaviour and constant stiffness above the critical section; evidence shows that the flexural stiffness of a wall varies during the dynamic response. Independently of the model used, most of the studies consider pushover analysis with different lateral load patterns (e.g. triangular or uniform), assuming the nature of the seismic demand. In this work, a parametric study of the yield displacement for cantilever slender $R C$ walls is presented. The results were obtained from nonlinear response history analyses (NRHA) for a set of cantilever $R C$ walls, representative of real wall buildings. To carry out NRHA, natural and artificial records with different features are used. Additionally, walls with different aspect ratio, height, thickness and longitudinal reinforcement are considered; walls were modelled with unidirectional fibres. The final discussion is focused on the influence of the higher mode effects in the yield displacement and its variability, in order to provide useful and simple design recommendations.

Keywords: yield displacement, reinforced concrete, cantilever slender walls, seismic analysis
El desplazamiento de fluencia es un parámetro importante para el diseño sísmico de muros esbeltos de hormigón armado en voladizo. Comúnmente es utilizado para diseñar elementos de borde y confinamiento, en función de las demandas de ductilidad esperada. En los últimos años han sido propuestas variadas expresiones para estimar el desplazamiento de fluencia, la mayoría de los estudios considera elementos con plasticidad concentrada, comportamiento elástico y rigidez constante sobre la sección crítica del muro, aunque la evidencia experimental muestra que la rigidez flexural varía durante la respuesta. Independiente del tipo de modelación considerada, gran cantidad de estudios realizan análisis estáticos incrementales (pushover) donde un determinado patrón de cargas laterales es asumido a priori (triangular, proporcional al primer modo de vibración, uniforme o puntual). En este trabajo se presentan los resultados de un estudio paramétrico realizado a muros esbeltos de hormigón armado, representativos de edificios con muros. Se utilizaron análisis no-lineal tiempo-historia considerando registros sísmicos naturales y sintéticos. Se usaron distintas características para los muros en relación a altura, espesor y cuantía de refuerzo; la modelación se hizo con fibras unidireccionales. La discusión final se orienta a la influencia de los modos altos y de su efecto en el desplazamiento de fluencia, con el objetivo de entregar recomendaciones de diseño.

Palabras claves: desplazamiento de fluencia, hormigón armado, muros esbeltos en voladizo, análisis sísmico

\section{Introduction}

Reinforced concrete (RC) slender walls, when ductility and inelastic displacement capacity to building appropriately designed and detailed, provide adequate structures. This behaviour is achieved by using boundary 
elements (confinement reinforcement), and by limiting the axial load and the concrete compressive strains in the wall. Currently, the Chilean provisions that are contained in DS60 (2011), limit the maximum concrete strain in the fibre of extreme compression $\left(\varepsilon_{c}\right)$, as shown in equations (1) and (2).

Regarding the displacement capacity of RC walls, according to DS60 (2011), at the critical section of slender walls with an aspect ratio $\left(H_{w} / L_{w}\right)$ greater than 3 the curvature capacity $(\phi)$ should be greater than the curvature demand $\left(\phi_{u}\right)$, in order to obtain a ductile behaviour and displacement capacity higher than the displacement demand $\left(\delta_{u}\right)$. The curvature demand can be estimated using the equations (1) or (2):

$$
\begin{aligned}
& \phi_{u}=\frac{2 \delta_{u}}{H_{w} L_{w}} \leq \frac{\varepsilon_{c}}{C}=\frac{0.008}{C} \\
& \phi_{u}=\frac{\left(\delta_{u}-\delta_{y}\right)}{L_{p}\left(H_{w}-\frac{L_{p}}{2}\right)}+\phi_{y} \leq \frac{\varepsilon_{c}}{C}=\frac{0.008}{C}
\end{aligned}
$$

where $L_{w}$ is the wall length, $L_{p}$ is the plastic hinge length, $\delta_{u}$ is the design displacement according to DS61 (2011), $\delta_{y}$ is the elastic displacement capacity (or yield displacement), $\phi_{y}$ is the yield curvature, $C$ is the distance from the extreme compression fibre to the neutral axis and $H_{w}$ is the wall height measured from the critical section. To estimate the curvature capacity, the maximum axial load on the wall must be considered; moreover, it is necessary to justify the values for $\phi_{y}$ and $\delta_{y}$ used in the analysis (DS60, 2011). However, Chilean regulations do not provide recommendations to compute these values. In addition, if equation (2) is analyzed, it is observed that the yield displacement is a key parameter in order to design RC slender walls, therefore, a reliable estimation of this value is required.

Previous studies have proposed closed-form expressions to estimate the elastic displacement capacity. However, most of these studies are based on pushover analyses, where the dynamic phenomenon is simplified to a fixed or variable lateral load pattern. An exception is presented by Quintana (2018), who proposes a relationship between the elastic displacement and a dynamic amplification factor, that is used in the capacity design for shear of cantilever walls (Paulay and Priestley, 1992), and that is a function only of the number of stories in the building. However, more recent studies have demonstrated that the dynamic amplification factor depends on the ductility demand too (Priestley et al., 2007; Morales, 2017; Jiménez et al., 2019; Morales et al., 2019).

Another common assumption, to estimate the elastic displacement capacity (or yield displacement) for slender $\mathrm{RC}$ walls, is that the flexural stiffness above the critical section is constant along the wall height. This assumption is not appropriate since the flexural stiffness of a wall varies during the dynamic response depending on its level of deformation (Beyer et al., 2014; Moehle, 2015). Additionally, due to the fact that for RC members the effective flexural stiffness is proportional to the nominal flexural strength (Priestley, 2003; Priestley et al., 2007), the axial force and its variation along the wall height has a relevant influence on the flexural stiffness that cannot be ignored. Furthermore, in the upper regions of the wall, the moment demands may be less than the cracking moment, therefore, the flexural stiffness should be larger than that of the lower stories (Priestley et al., 2007; Adebar et al., 2007).

In some cases, assumptions and simplifications considered in previous studies could produce errors in the estimation of the yield displacement and, as a consequence, inadequate design of wall boundary elements (i.e., underestimation of confinement reinforcement or wall thickness).

Considering the previous ideas, in this paper, a parametric study of the yield displacement for slender cantilever RC walls is presented. The results were obtained from nonlinear response history analyses (NRHA) for a set of cantilever RC walls, representative of real wall buildings. The building prototypes were created by varying the wall aspect ratio, height, thickness and longitudinal reinforcement, and were modelled using a distributed inelasticity fibre model. To carry out NRHA, natural and artificial records with different features are used. The displacement at which first yielding occurs is recorded in order to correlate it with features of the wall such as aspect ratio, amount of reinforcement, and the accelerograms characteristics (intensity, frequency content). The final discussion is focused on the influence of higher mode effects on the yield displacement and its variability, in order to provide design recommendations. 


\section{Description of the analytical model}

The analysis model was implemented in SeismoStruct (Seismosoft, 2018) using a classical forced-based fibre element formulation in which the wall cross-section is discretized into uniaxial fibres representing the reinforcing steel and the confined (concrete core) and unconfined concrete (concrete cover). This formulation assumes that plane sections remain plane during the deformation history (the Bernoulli hypothesis); hence shear deformations are not accounted for in the analysis. On the other hand, a relevant aspect of this modelling approach is that calibration of the input parameters is not required and that axial-flexural interaction can be explicitly captured. Therefore, the model is able to represent the elastic and inelastic stiffness of the members with a non-critical shear or flexure-shear response (Sedgh et al., 2015).

In this study single cantilever walls are used as a simplification to represent a building (see Figure 1). This approach has been used in the past by other authors (Priestley and Amaris, 2002; Pennucci et al., 2013); however, some improvements are included in this work. In order to make the analysis as general as possible, 10-, 15-, 20-, 25- and 30-story buildings are considered and, for each building height, three different rectangular cross-sections are defined (see Figure 2 and Table 1). Note that the axial load ratios (ALR) were selected considering typical values found in the design practice of RC wall buildings in Chile.

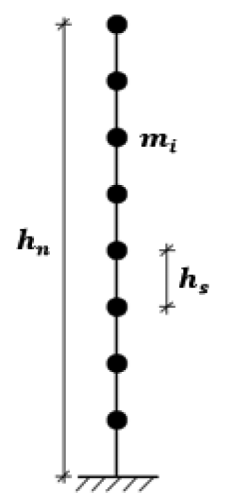

$$
\begin{aligned}
& \boldsymbol{m}_{i}: \text { Story mass } \\
& \boldsymbol{h}_{\boldsymbol{n}}: \text { Building height } \\
& \boldsymbol{h}_{\boldsymbol{s}}: \text { Inter-story height }
\end{aligned}
$$

Figure 1: Building numerical model

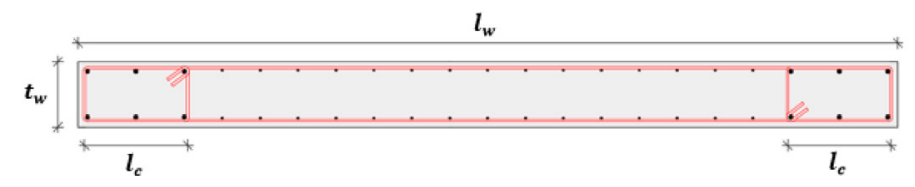

Figure 2: Rectangular wall cross-section
Table 1: Characteristics of the building prototypes

\begin{tabular}{|c|c|c|c|c|c|c|c|c|}
\hline $\begin{array}{c}\text { Proto- } \\
\text { type }\end{array}$ & $\rho_{l}, \%$ & $l_{w}, \mathrm{~m}$ & $l_{c}, \mathrm{~m}$ & $t_{w}, \mathrm{~m}$ & $h_{n}, \mathrm{~m}$ & $h_{s}, \mathrm{~m}$ & $\begin{array}{c}m_{i}, \\
\text { ton }\end{array}$ & ALR \\
\hline W.1 & 0.31 & 8.0 & 1.2 & 0.25 & 27.0 & 2.7 & 60.0 & 0.20 \\
\hline W.2 & 0.30 & 6.0 & 0.8 & 0.25 & 27.0 & 2.7 & 25.0 & 0.15 \\
\hline W.3 & 0.32 & 4.0 & 0.8 & 0.25 & 27.0 & 2.7 & 5.0 & 0.15 \\
\hline W.4 & 0.31 & 12.0 & 1.2 & 0.25 & 40.5 & 2.7 & 70.0 & 0.20 \\
\hline W.5 & 0.31 & 8.0 & 0.8 & 0.25 & 40.5 & 2.7 & 20.0 & 0.15 \\
\hline W.6 & 0.33 & 6.0 & 0.8 & 0.25 & 40.5 & 2.7 & 60.0 & 0.35 \\
\hline W.7 & 0.36 & 15.0 & 2.0 & 0.30 & 54.0 & 2.7 & 80.0 & 0.20 \\
\hline W.8 & 0.38 & 10.0 & 1.6 & 0.30 & 54.0 & 2.7 & 20.0 & 0.15 \\
\hline W.9 & 0.37 & 8.0 & 1.2 & 0.30 & 54.0 & 2.7 & 60.0 & 0.30 \\
\hline W.10 & 0.41 & 15.0 & 2.0 & 0.30 & 67.5 & 2.7 & 60.0 & 0.20 \\
\hline W.11 & 0.44 & 10.0 & 1.6 & 0.30 & 67.5 & 2.7 & 6.0 & 0.15 \\
\hline W.12 & 0.43 & 8.0 & 1.2 & 0.30 & 67.5 & 2.7 & 6.0 & 0.15 \\
\hline W.13 & 0.41 & 15.0 & 2.0 & 0.35 & 81.0 & 2.7 & 26.0 & 0.15 \\
\hline W.14 & 0.43 & 10.0 & 1.6 & 0.35 & 81.0 & 2.7 & 6.0 & 0.15 \\
\hline W.15 & 0.42 & 8.0 & 1.2 & 0.35 & 81.0 & 2.7 & 10.0 & 0.20 \\
\hline
\end{tabular}

Story masses showed in Table 1 were adjusted to obtain first-mode elastic periods representative of real wall structures. This consideration is not trivial since, as shown by Morales (2017) and Morales et al. (2019), previous studies with similar modelling approaches have resulted in building models with first-mode elastic periods larger than what is expected from real structures. The periods of the buildings from this study are compared against the expressions proposed in ASCE 7-10 (2010) and in Massone et al. (2012), the latter based on the values measured by Wood et al. (1987). The expressions are reproduced below as equations (3) and (4), respectively.

$$
\begin{aligned}
& T_{a}=C_{t} h_{n}^{x} \\
& T_{a}=\frac{N}{15}
\end{aligned}
$$

In equation (3) $h_{n}$ is the building height and the coefficients $C_{t}$ and $x$ are 0.0488 and 0.75 , respectively. On the other hand, in equation (4) $N$ represents the number of stories of the building. Figure 3 compares the periods of the buildings considered in this study with the periods predicted using equations (3) and (4). It is observed a good correlation between the values obtained in this study and the empirical expressions. 


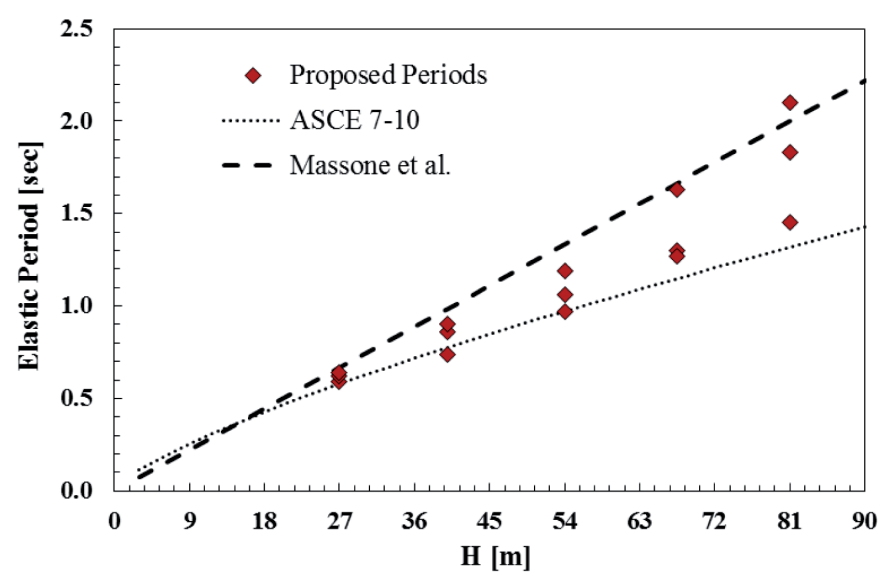

Figure 3: Comparison between first mode periods obtained in this study and expressions proposed in the literature

\section{Materials: concrete and reinforcement steel}

A trilinear concrete model (named con_tl in SeismoStruct) was used for the confined and unconfined regions of the wall. The con_tl is a simplified uniaxial model that assumes no resistance in tension and features a residual strength plateau in compression. Five parameters must be defined in order to fully describe the mechanical characteristics of the material: mean compression strength $\left(f_{c 1}\right)$, initial stiffness $\left(E_{1}\right)$, post-peak stiffness $\left(E_{2}\right)$, residual strength $\left(f_{c 2}\right)$ and specific weight $\left(y_{c}\right)$. The parameters used in this study are as shown in Table 2.

Table 2: Concrete model parameters

\begin{tabular}{|c|c|c|}
\hline Parameter & Unconfined & Confined \\
\hline$f_{c 1}, \mathrm{MPa}$ & 25 & 29 \\
\hline$E_{1}, \mathrm{MPa}$ & 13000 & 15600 \\
\hline$E_{2}, \mathrm{MPa}$ & -5500 & -6600 \\
\hline$f_{c 2}, \mathrm{MPa}$ & 5 & 6 \\
\hline$y_{c}, \mathrm{kN} / \mathrm{m}^{3}$ & 24 & 24 \\
\hline
\end{tabular}

To represent the cyclic behaviour of the reinforcement steel the model of Menegotto-Pinto (1973), included in SeismoStruct, was selected. This is a uniaxial model with the isotropic hardening rules as proposed by Filippou et al. (1983). An additional memory rule proposed by Fragiadakis et al. (2008) is also introduced for higher numerical stability and accuracy under transient seismic loading (Seismosoft, 2018). Table 3 shows the ten parameters used in this study to calibrate the Menegotto-Pinto model.
Table 3: Reinforcement model parameters

\begin{tabular}{|l|c|}
\hline Parameter & Considered value \\
\hline Modulus of elasticity $E_{s}, \mathrm{MPa}$ & 200000 \\
\hline Yield strength $f_{y}, \mathrm{MPa}$ & 420 \\
\hline Strain hardening parameter $\mu$ & 0.01 \\
\hline Transition curve initial shape parameter $R_{o}$ & 20 \\
\hline Transition curve shape calibrating coefficient A1 & 18.5 \\
\hline Transition curve shape calibrating coefficient A2 & 0.15 \\
\hline Isotropic hardening calibrating coefficient A3 & 0.0 \\
\hline Fracture/buckling strain & 0.1 \\
\hline Specific weight $y_{s}, \mathrm{kN} / \mathrm{m}^{3}$ & 78 \\
\hline
\end{tabular}

The material models for concrete and reinforcement steel were selected after a trial and error procedure in which the performance of four different material models was compared against the experimental results of Thomsen and Wallace $(1995$; 2004) for a RC rectangular wall specimen (specimen RW2). For this purpose, an analytical model of the specimen was developed in SeismoStruct (SeismoSoft, 2018) and was subjected to the same loading protocol implemented by the authors. The analytical results are shown in Figure 4, for the selected con_ctl and MenegotoPinto material models, and are compared against the experimental ones. It is noticeable the close match between the simulation and the experimental data which furthers validate the modelling approach implemented here. For more details about the analysis model, its definition and calibration, the reader is referred to the work of Rubina (2020).

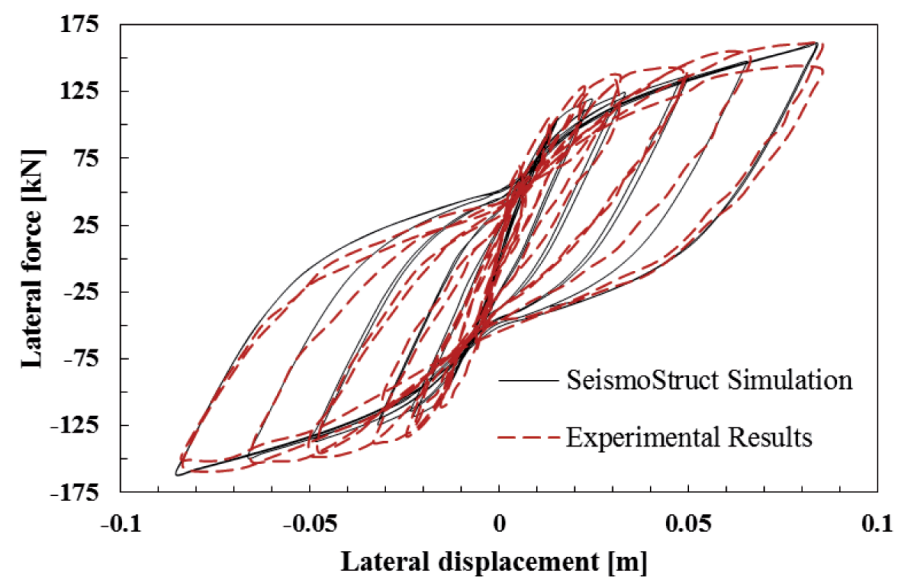

Figure 4: Analytical and experimental results, specimen RW2 


\section{Nonlinear response history analysis (NRHA)} and results

To carry out the NRHA of the simplified buildings a set of six accelerograms was considered: three artificial (Figure 5a, $5 \mathrm{c}$ and $5 \mathrm{e}$ ) and three natural records (Figure 5b, 5d and 5f).

Note that the duration of the natural accelerograms presented in the Figure 5 was reduced to an effective duration in order to obtain shorter analysis times. The concept of effective duration refers to the duration of the strong motion phase of an earthquake recording measured from an Arias Intensity (AI) versus time plot (or Husid plot). Bommer and Martinez-Pereira (1999) proposed to

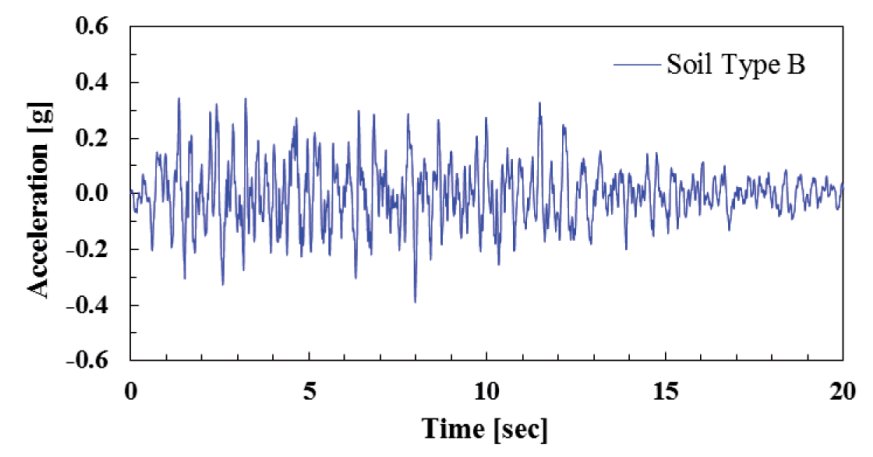

(a)

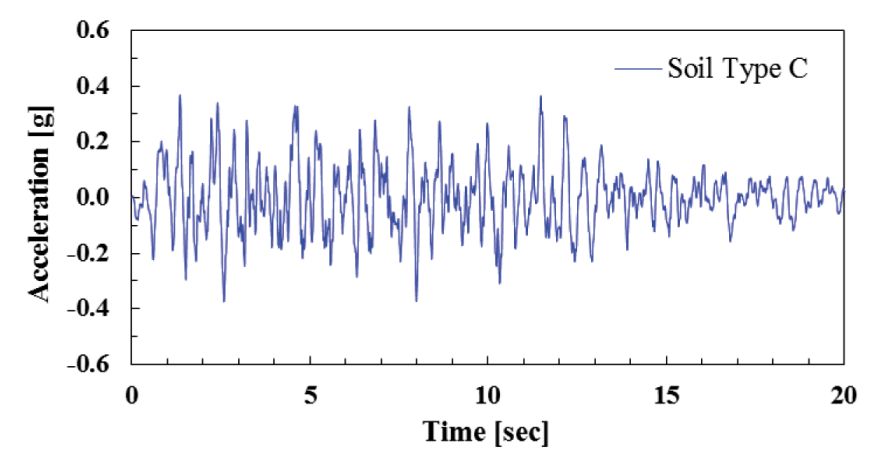

(c)

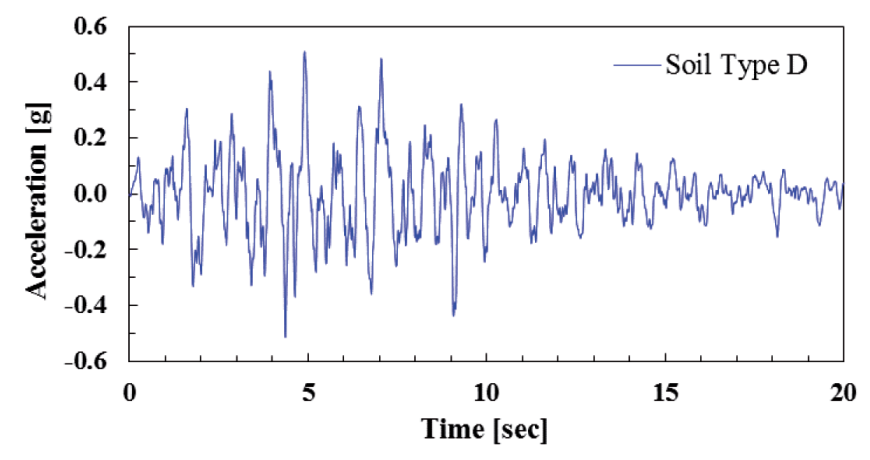

(e) define the beginning of the strong motion phase as the instant when $\mathrm{AI}$ is $0.01 \mathrm{~m} / \mathrm{s}$ and pointed out that AI less than $0.135 \mathrm{~m} / \mathrm{s}$ do not have an effective duration since they are not considered to be strong motions.

The artificial accelerograms were generated with SeismoArtif v2016 (Seismosoft, 2016) to be compatible with the elastic pseudo-acceleration spectra defined in DS61 (2011) for soil types B, C and D in seismic zone III. Response spectra of the artificial accelerograms are shown as dotted lines in Figure 6b and, as expected, they match the code spectra (solid lines) in a wide period range with comparatively small dispersion. Regarding the natural

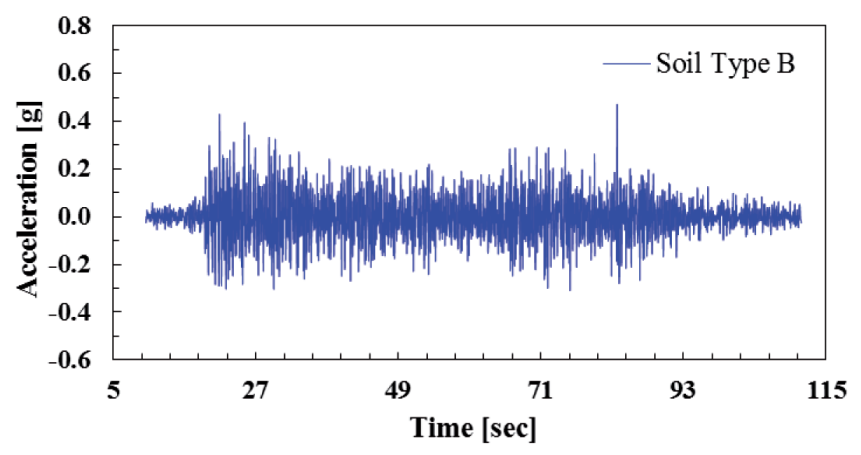

(b)

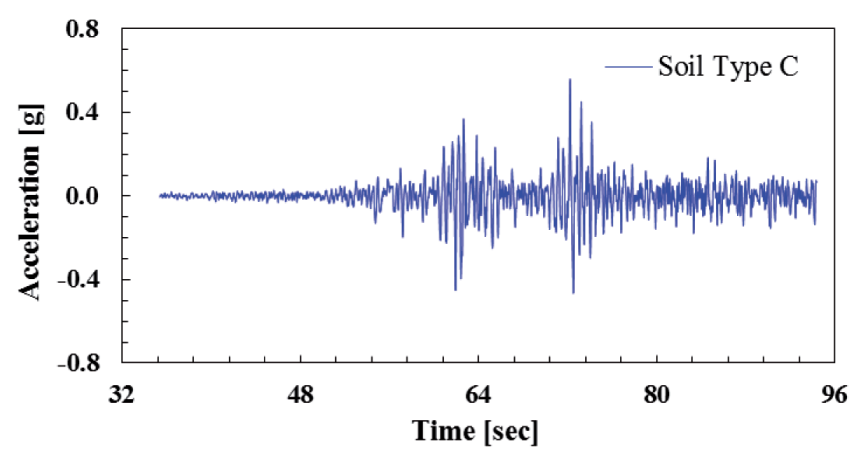

(d)

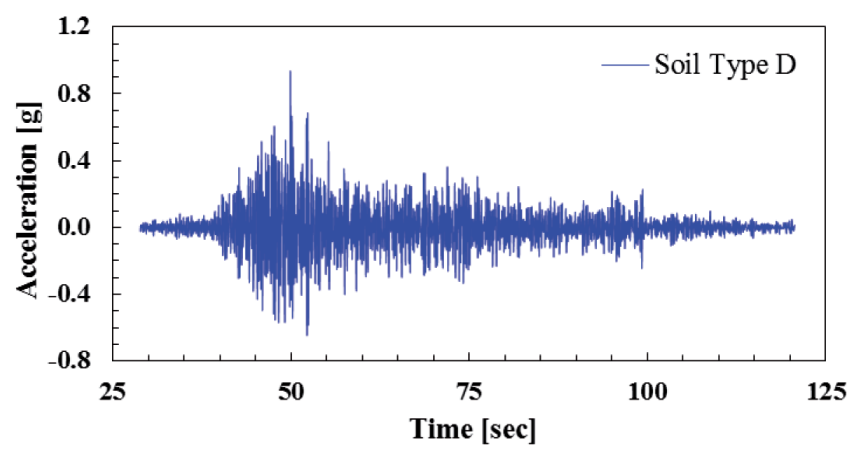

(f)

Figure 5: Artificial and natural accelerograms 
accelerograms, three recorded ground motions in Chile from 2010 are considered in this study: Angol NS (soil type $\mathrm{D}$ and seismic zone III), Maipu NS (soil type D and seismic zone II) and Talca NS (soil type B and seismic zone III). Figure 6a shows the elastic pseudo-acceleration spectra for $5 \%$ damping, obtained from the natural recordings (dotted line), and their comparison with the elastic spectra from NCh433 (2009) (solid lines).
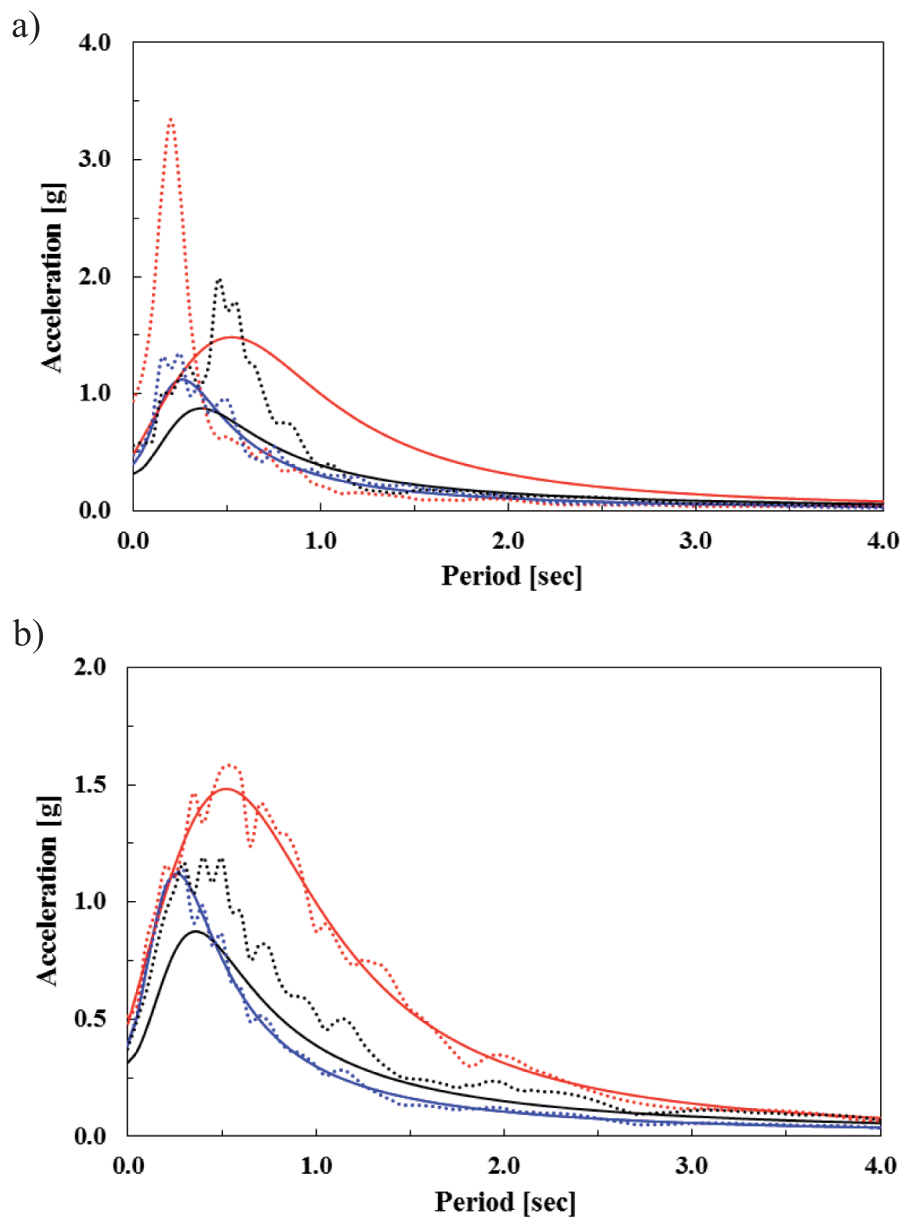

Figure 6: Pseudo-acceleration spectra: (a) natural accelerograms and (b) artificial accelerograms

\section{Yield displacement}

In this section, the results of the NRHA are presented and discussed in terms of the yield displacement of the case study buildings (see Figure 1). In order to estimate the yield displacement, the yield curvature at the base of the walls is considered according to equation (5) proposed by Priestley (1998). In this case the yield curvature is defined as the lowest between the curvature at the first yielding of tension reinforcement, or the curvature when the extreme fibre reaches a compressive strain of 0.002 , extrapolated to the nominal flexural strength (Priestley, 1998).

$$
\phi_{y}=2.0 \frac{\varepsilon_{y}}{L_{w}} \pm 0.1 \frac{1}{L_{w}}
$$

In the equation above, $L_{w}$ is the wall length and $\varepsilon_{y}$ is the yield strain of the longitudinal reinforcement. As shown in equation (5), the yield curvature $\left(\phi_{y}\right)$ is defined with a lower and upper limit due to the dispersion observed in experimental tests. In order to consider the variability observed in laboratory tests and achieve representative results, this work used three different values of $\phi_{y}$ for each wall prototype. In this manner it is possible to account for the uncertainty in the definition of the yield curvature, and in the estimation of the yield displacement of the wall prototypes.

Commonly, the yield displacement $\delta_{y}$ in slender walls is presented in terms of the yield curvature $\phi_{y}$, the wall height $h_{w}$ and a dimensionless yield constant $k_{y}$, as shown in equation (6). This constant is a function of lateral load pattern applied to the wall and, according to the literature, could take values between 0.15 and 0.33 .

$$
\delta_{y}=K_{y} \phi_{y} h_{w}^{2}
$$

Using the NRHA results and based on the equation (6), this paper proposes values for $k_{y}$ that includes features of the earthquake ground motions considered. To accomplish this goal, the following procedure is applied:

For each wall section upper $\left(\phi_{y}^{U}\right)$, lower $\left(\phi_{y}^{L}\right)$ and average $\left(\overline{\phi_{y}^{A}}\right)$ curvature values are estimated from equation (5).

From NRHA the curvature time history response at the base of walls is obtained, and the time instant at which the upper, lower and average yield curvatures occur is identified. Then, using the roof displacement time history and the time instants identified previously, three values for the yield displacement $\left(\delta_{y}^{L}, \delta_{y}^{A}\right.$ and $\left.\delta_{y}^{U}\right)$ are found.

Finally, applying the equation (7), three values for the dimensionless yield constant $K_{v}$ are estimated for each nonlinear response history analysis carried out.

$$
K_{y}^{L}=\frac{\delta_{y}^{L}}{\phi_{y}^{L} h_{w}^{2}}
$$




$$
\begin{aligned}
& K_{y}^{A}=\frac{\delta_{y}^{A}}{\phi_{y}^{A} h_{w}^{2}} \\
& K_{y}^{U}=\frac{\delta_{y}^{U}}{\phi_{y}^{U} h_{w}^{2}}
\end{aligned}
$$

In the following paragraphs, the results of the NRHA campaign carried out in this study are presented in terms of the dimensionless constant $K_{y}$ and the stiffness index $H / T$ (Lagos et al., 2012, 2020), which is defined as the ratio between the total building height above the ground level and the first translational natural period in the direction of analysis. Figures $7 \mathrm{a}, 7 \mathrm{~b}$ and $7 \mathrm{c}$ show the values of the dimensionless yield constants $\left(K_{y}^{L}, K_{y}^{A}\right.$ and $\left.K_{y}^{U}\right)$ obtained for soil types B, C and D, respectively, from the analyses with artificial accelerograms. It is observed that small variations in the estimation of the yield curvatures

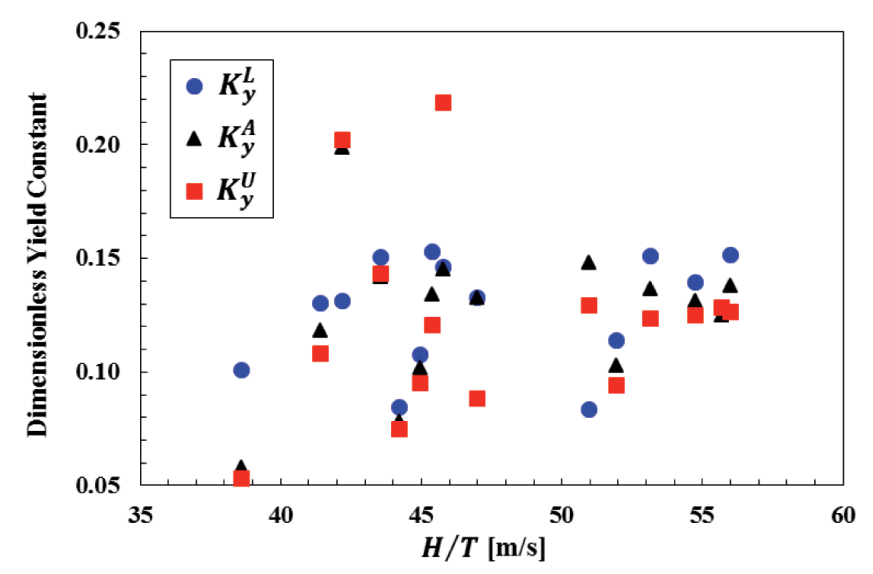

(a)

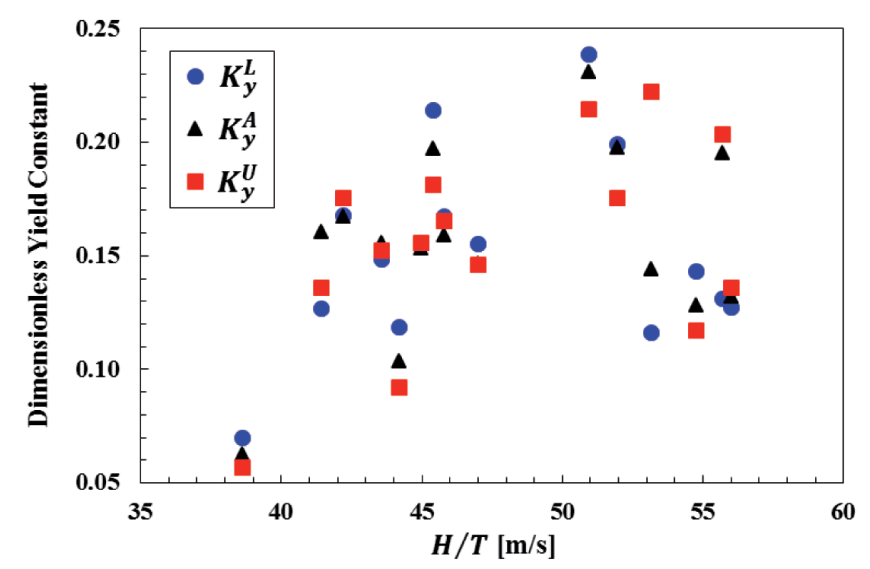

(c) can produce large changes (or dispersion) in the yield displacement values. For stiffness indices larger than 40 $\mathrm{m} / \mathrm{s}$, the plots show that the dimensionless yield constant increases as the $H / T$ ratio also increases. From the scatter plot in Figure 7d, that summarizes the results for the three soil types, it is established that the dimensionless yield constants take values between 0.05 and 0.25 and that there is not any apparent correlation with the soil type.

Similarly, Figure 8 presents the results obtained from NRHA using natural accelerograms. In comparison with the artificial accelerograms, the same tendency is observed: lack of a clear correlation between the dimensionless yield constant and the soil type, mainly for soils type C and D (Figures $8 \mathrm{~b}$ and $8 \mathrm{c}$ ). However, in this case, $K_{y}$ takes values between 0 and 0.25 showcasing a dispersion larger than that observed from the artificial accelerograms (see Figure $8 d)$.

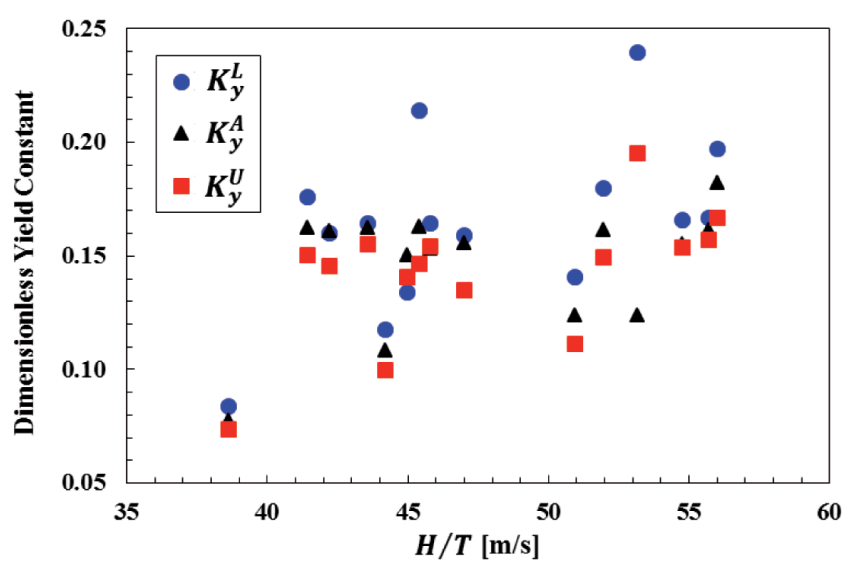

(b)

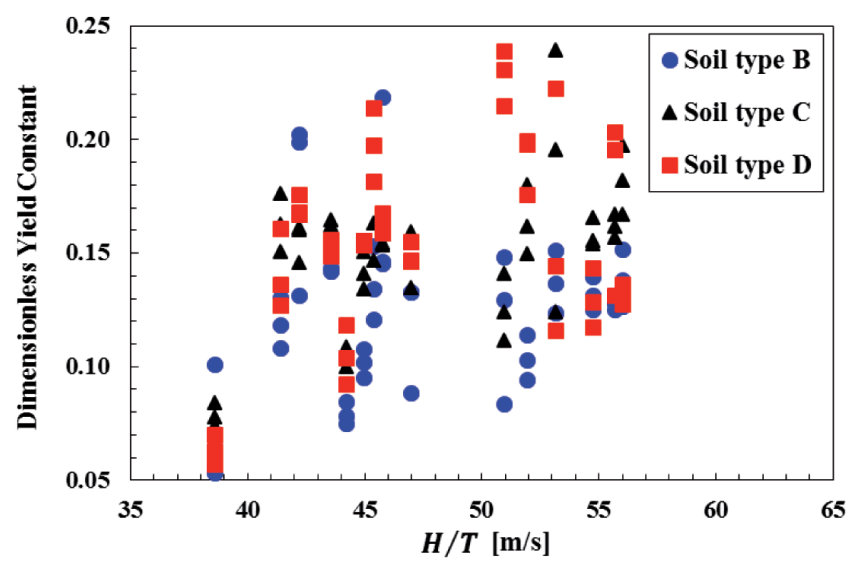

(d)

Figure 7: Dimensionless yield constants for artificial accelerograms: (a) soil type B, (b) soil type C, (c) soil type D and (d) summary results 


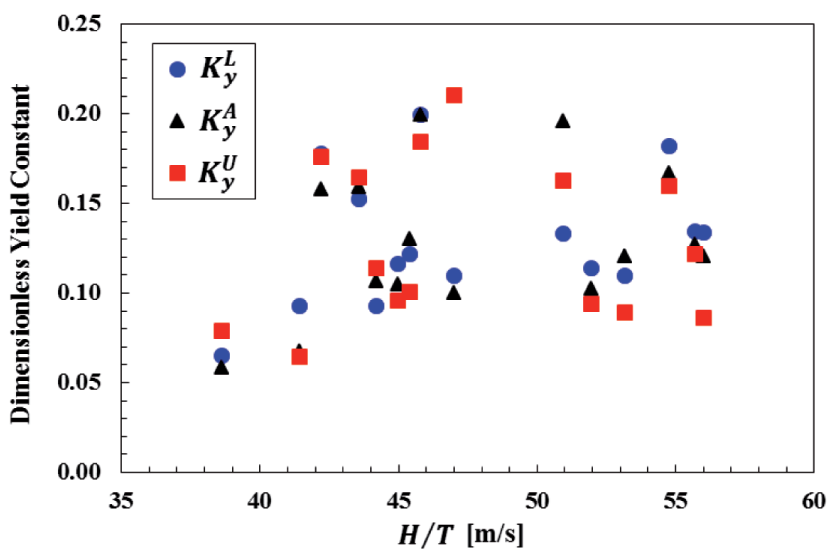

(a)

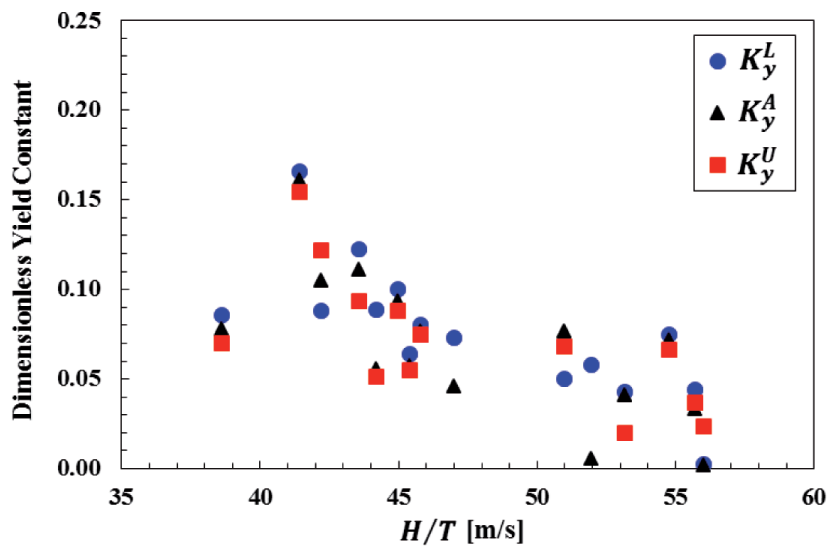

(c)

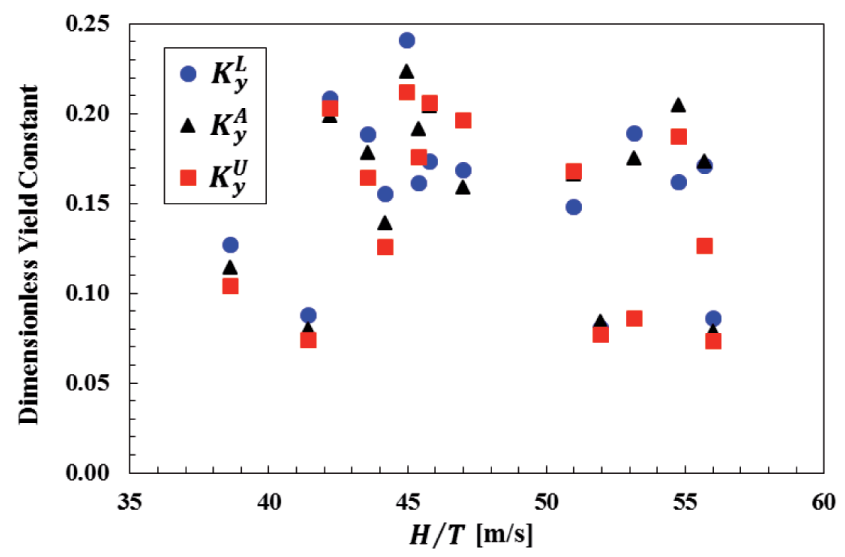

(b)

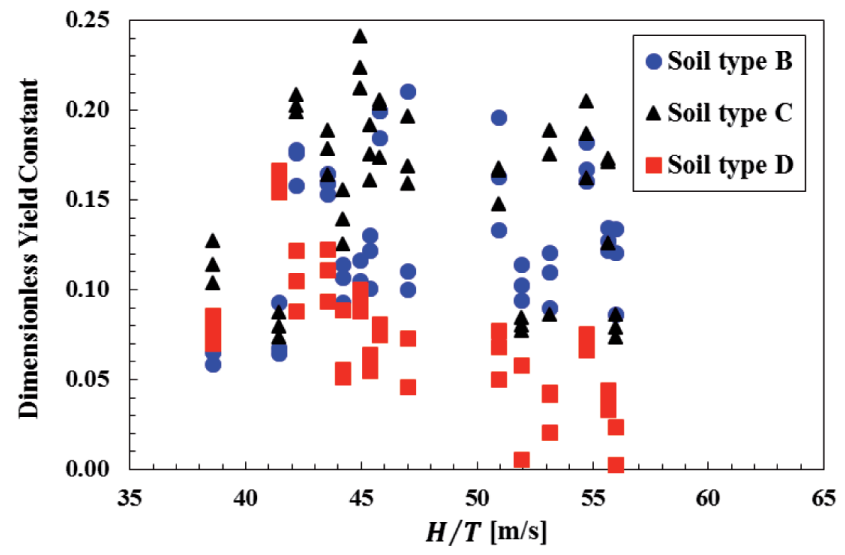

(d)

Figure 8: Dimensionless yield constants for natural accelerograms: (a) soil type B, (b) soil type C, (c) soil type D and (d) summary results

Even though an evident correlation between the dimensionless yield constant, the soil type and the building stiffness index is not shown in Figures $7 \mathrm{~d}$ and $8 \mathrm{~d}$, an interesting result is observed: a good definition of the minimum values of $K_{y}$ as a function of the building stiffness index. Based on this finding, a simple and practical expression to estimate the yield displacement is proposed, as shown below.

\section{Influence of higher-mode effects}

The pattern of lateral inertial forces in wall buildings changes during the dynamic response. At some instants of the response, displacement and accelerations may be strongly influenced by the second and third modes of vibration (Paulay and Priestley, 1992). If the wall is designed to have a single critical section (or plastic hinge) for moment and axial force, moments at critical section are bounded by the provided moment strength. However, moment and shear elsewhere are not well limited due to the changes in the lateral inertial forces (Moehle, 2015).

Analytical and experimental results show that the base shear demand is a function of two factors. Firstly, the moment strength at the base of the wall and, secondly, the distribution of lateral inertial forces. If the pattern of the lateral forces is close or approximately proportional to the first mode shape, the centroid of lateral forces $\left(h_{v}\right)$ is typically located around 0.7 (see Figure 9a). However, if the dynamic response is strongly influenced by higher modes, the resultant force is located much lower than in the previous case with an increment of the base shear, as shown in Figure 9b. 
a)

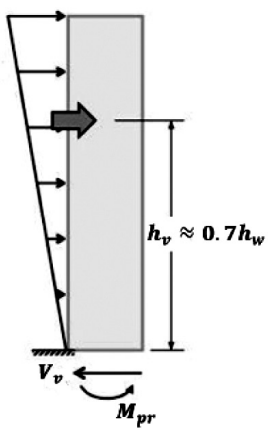

b)

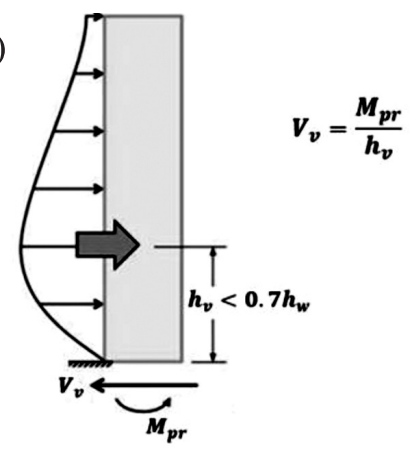

Figure 9: Relation between base shear and lateral inertial force profile, adapted from Moehle (2015)

According to previous ideas, the influence of highermode effects can be visualized studying the position of the centroid of lateral forces. If the value of $h_{v} / h_{w}$ is less than 0.7 , the dynamic response is influenced by higher-modes. In fact, the value of $h_{v} / h_{w}$ decreases as the higher-mode effects increase.

Figure 10 shows the dimensionless yield constant $K_{y}$ as a function of the centroid of lateral forces, it is noted that most of the values of $h_{v} / h_{w}$ are less than 0.7. However, a tendency is observed: the influence of higher-mode effects increase as the values of $K_{y}$ decrease, mainly for the results obtained with artificial accelerograms.

a)

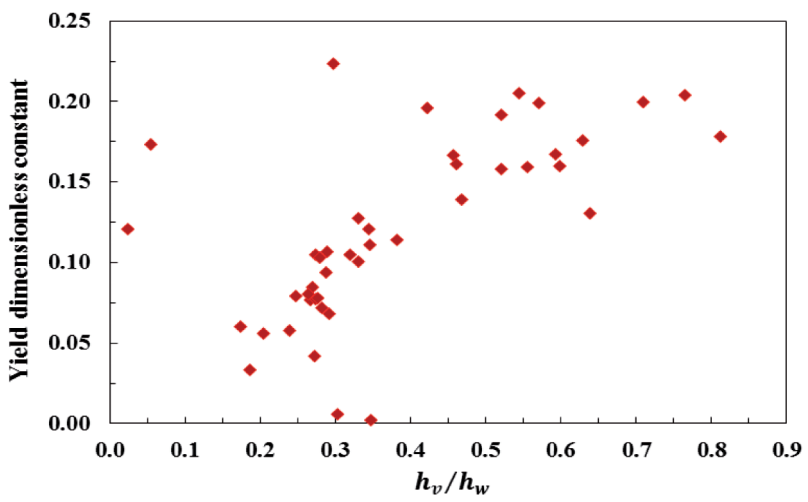

b)

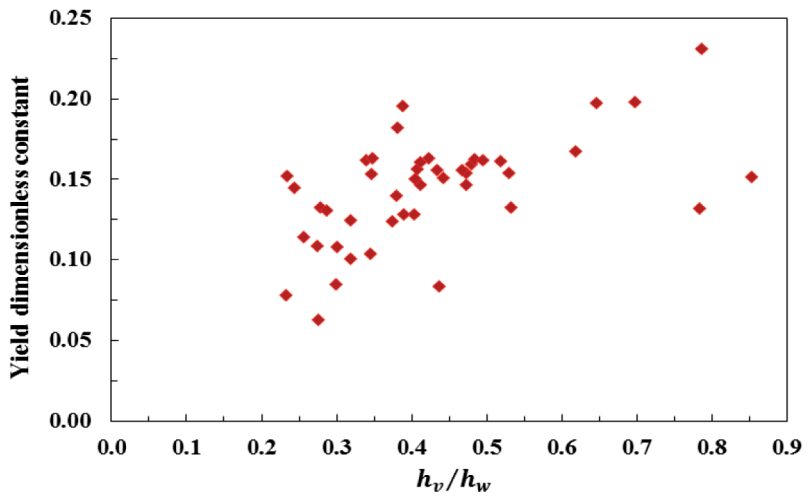

Figure 10: Centroid of lateral forces: (a) natural accelerograms and (b) artificial accelerograms

\section{Proposed expression to estimate the yield displacement}

As mentioned above, a clear relationship or correlation between the dimensionless yield constant and the soil types and building stiffness indices is not detected. Figure 11 summarizes all the results obtained from NRHA where, despite the scatter of the data, upper and lower limits of the $K_{y}$ values are identified. These limits define a band of points which decreases as the building stiffness index increases. The main objective of this study is to provide a simple and conservative expression to estimate the yield displacement in slender cantilever reinforced concrete walls. Therefore, the expression proposed makes use of the lower limit of the data showed in Figure 11 (dashed black line).

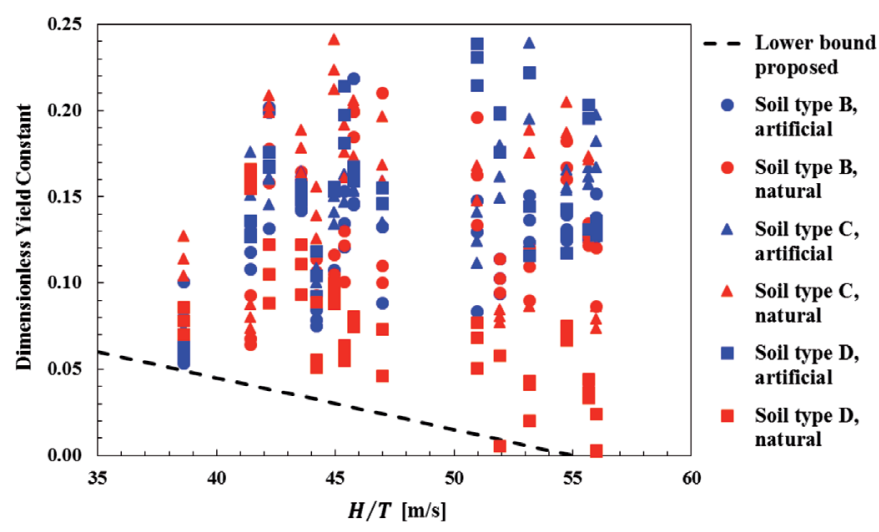

Figure 11: Dimensionless yield constants

The yield displacement of a cantilever wall building is estimated as per equation (6), which for convenience is rewritten here as equation (8). As stated above, using only the lower limit of the scatter plot in Figure 11, the dimensionless yield constant can be estimated as a function of the building index $H / T$ as proposed in equation (9). Note that for building stiffness indexes larger than $55 \mathrm{~m} / \mathrm{s}$ the yield displacement of slender cantilever walls is neglected.

$$
\delta_{y}=K_{y} \phi_{y} h_{w}^{2}
$$

with

$K_{y}=\left\{\begin{array}{cc}0.003 \frac{H}{T}-0.165 & 35 \mathrm{~m} / \mathrm{s} \leq \frac{H}{T} \leq 55 \mathrm{~m} / \mathrm{s} \\ 0 & 55 \mathrm{~m} / \mathrm{s}<\frac{H}{T}\end{array}\right.$ 
Regarding the applicability of the equation (9), it shall be limited to the range of case study buildings considered here, and to wall buildings with stiffness indexes between $35 \mathrm{~m} / \mathrm{s}$ and $55 \mathrm{~m} / \mathrm{s}$. To increase this range, further analyzes are required.

\section{Conclusions and future research}

In this paper, a simple and useful expression to compute yield displacement of slender cantilever RC walls was presented. This expression is more conservative than previous approaches presented in the literature and only depends on the building stiffness index, which is a common and available parameter for structural designers. Several analytical improvements were introduced in this study; for instance, the wall flexural stiffness was defined as a function of the moment capacity, the use of distributed inelasticity fibre elements along the wall height, explicit seismic demands (accelerograms) and a good representation of the reinforced concrete wall buildings using their stiffness indices. Furthermore, the axial load ratios and natural periods of the prototypes analyzed are representative of real wall buildings.

With regard to the effects of higher-modes, it should be noted that their influence increases with the increase of the building period; nonetheless, further analyses are required to obtain reliable results.

During the development of this research, a certain number of approximations and assumptions were necessary. Some of these assumptions may introduce uncertainty to the findings presented. Future research is focused to give answers to the potential sources of uncertainty. Firstly, this study only considered the analysis of one configuration of buildings, represented as single cantilever rectangular wall with different features (thickness, aspect ratio and reinforcement amount). In order to extrapolate the results of this study, non-rectangular walls (e.g. C- and T-shaped wall) could be considered in future works. Finally, analysis models (or prototypes) with two or more walls acting in parallel should be used to account for their interaction and possible coupling within the building.

\section{Acknowledgments}

The authors gratefully acknowledge the suggestions and comments of Dr. Héctor Pérez and Professor Wendy Wiegand which contributed to improving this paper.

\section{References}

Adebar, P., Ibrahim, A. and Bryson, M. (2007). Test of high-rise core wall: effective stiffness for seismic analysis. ACI Structural Journal 104(5), 549-559

ASCE 7-10 (2010). Minimum design loads for buildings and other structures. American Society of Civil Engineers, Reston, Virginia, USA

Beyer, K., Simonini, S., Constantin, R. and Rutenberg, A. (2014). Seismic shear distribution among interconnected cantilever walls of different lengths. Earthquake Engineering \& Structural Dynamics 43(10), 1423-1441

Bommer, J. and Martínez-Pereira, A. (1999). The effective duration of earthquake strong motion. Journal of Earthquake Engineering 3(2), 127-172

DS61 (2011). Decreto Supremo N61. Reglamento que fija el diseño sísmico de edificios y deroga Decreto No 117 , de 2010. Ministerio de Vivienda y Urbanismo, Diario Oficial de la República de Chile, No 40.133, 8-12

DS60 (2011). Decreto Supremo 60. Reglamento que fija los requisitos de diseño y cálculo para el hormigón armado y deroga Decreto $\mathrm{N}^{\circ} 118$, de 2010. Ministerio de Vivienda y Urbanismo, Diario Oficial de la República de Chile, № 40.133, 1-8

Filippou, F.C., Popov, E.P. and Bertero, V.V. (1983). Effects of bond deterioration on hysteretic behaviour of reinforced concrete joints. Report EERC 83-19, Earthquake Engineering Research Center, University of California, Berkeley, USA

Fragiadakis, M., Pinho, R. and Antoniou, S. (2008). Modelling inelastic buckling of reinforcing bars under earthquake loading. In Computational Structural Dynamics and Earthquake Engineering, M. Papadrakakis, D.C. Charmpis, N.D. Lagaros and Y. Tsompanakis (eds.), A.A. Balkema Publishers - Taylor \& Francis, The Netherlands, 347-362

Jiménez, F., Massone, L., Macaya, F. y Bass, E. (2019). Amplificación dinámica del corte en muros de H.A. con estructuración chilena. XII Congreso Chileno de Sismología e Ingeniería Sísmica ACHISINA, Valdivia, Chile, artículo 1539

Lagos, R., Lafontaine, M., Bonelli, P., Boroschek, R., Guendelman, T., Massone, L., Saragoni, R., Rojas, F. and Yañez, F. (2020). The quest for resilience: The Chilean practice of seismic design for reinforced concrete buildings. Earthquake Spectra 37(1), 26-45 
Lagos, R., Kupfer, M., Lindenberg, J., Bonelli, P., Saragoni, R., Guendelman, T., Massone, L., Boroschek, R. and Yañez, F. (2012). Seismic performance of high-rise concrete buildings in Chile. International Journal of High-Rise Buildings 1(3), 181-194

Massone, L.M., Bonelli, P., Lagos, R., Lüders, C., Moehle, J. and Wallace, J.W. (2012). Seismic design and construction practices for RC structural wall buildings. Earthquake Spectra 28(1), 245-256

Menegotto, M. and Pinto, P.E. (1973). Method of analysis for cyclically loaded reinforced concrete plane frames including changes in geometry and non-elastic behavior of elements under combined normal force and bending. Symposium on Resistance and Ultimate Deformability of Structures Acted on by WellDefined Repeated Loads, International Association for Bridge and Structural Engineering IABSE, Lisbon, Portugal, 15-20

Moehle, J. (2015). Seismic design of reinforced concrete buildings. McGraw-Hill Education, New York, USA

Morales, A. (2017). Seismic shear and moment demands in RC wall buildings. $\mathrm{PhD}$ thesis, Istituto Universitario di Superiori di Pavia (IUSS), Italy

Morales, A., Ceresa, P. and Hube, M. (2019). Seismic shear and moment demands in reinforced concrete wall buildings. $7^{\text {th }}$ International Conference on Computational Methods in Structural Dynamics and Earthquake Engineering, COMPDYN 2019, M. Papadrakakis and M. Fragiadakis (eds.), Crete, Greece. ECCOMAS Proceedia, 4115-4127

NCh433 (2009). Diseño sísmico de edificios. Norma Chilena Oficial NCh433 Of.96 modificada 2009. Instituto Nacional de Normalización, Santiago, Chile

Paulay, T. and Priestley, M.J. N. (1992). Seismic design of reinforced concrete and masonry structures. John Wiley \& Sons, New York, USA.

Pennucci, D., Sullivan, T.J. and Calvi, G.M. (2013). Inelastic higher-mode response in reinforced concrete wall structures. Earthquake Spectra 31(3), 1493-1514

Priestley, M.J.N. (2003). Myths and fallacies in earthquake engineering revisited. ROSE School report, Pavia, Italy

Priestley, M.J.N. (1998). Brief comments on elastic flexibility of reinforced concrete frames and significance to seismic design. Bulletin of the New Zealand Society for Earthquake Engineering 31(4), 246-259

Priestley, M.J.N. and Amaris, A. (2002). Dynamic amplification of seismic moments and shear forces in cantilever walls. Research report ROSE - 2002/01, IUSS press, Pavia, Italy

Priestley, M.J.N., Calvi G.M. and Kowalsky, M.J. (2007). Displacement-based seismic design of structures. IUSS PRESS, Pavia, Italy

Quintana Gallo, P. (2018). Simple estimation of the maximum elastic roof displacement of a slender cantilever RC wall accounting for dynamic effects. Obras y Proyectos 23, 55-62

Rubina, V. (2020). Desplazamiento de fluencia de muros de hormigón armado y su relación con el tipo de demanda. Trabajo de título, Universidad de Valparaíso, Chile

Sedgh, R.E., Dhakal, R.P. and Carr, A.J. (2015). State of the art: Challenges in analytical modelling of multi-storey shear wall buildings. New Zealand Society for Earthquake Engineering Annual Conference NZSEE, Rotorua, New Zealand, paper O-15, 139-150

Seismosoft (2016). SeismoArtif v2016. Available from http:// www.seismosoft.com.

Seismosoft (2018). SeismoStruct v2018 - A computer program for static and dynamic nonlinear analysis of framed structures. Available from http://www.seismosoft.com.

Thomsen, J.H. and Wallace, J.W. (1995). Displacement-based design of RC structural walls: Experimental studies of walls with rectangular and T-shaped cross sections. Report No.CU/CEE95/96, Department of Civil and Environmental Engineering, Clarkson University, USA

Thomsen, J.H. and Wallace, J.W. (2004). Displacementbased design of slender reinforced concrete structural walls Experimental verification. Journal of Structural Engineering 130(4), 618-630

Wood, S.L., Wight, J.K. and Moehle, J.P. (1987). The 1985 Chile earthquake, observations on earthquake resistant construction in Viña del Mar. Civil Engineering Studies. Structural Research Series No. 532, University of Illinois, Urbana, USA 